\title{
Performance analysis of Five-Phase and Three-Phase Induction Machines
}

\author{
Loriya Vismay J. ${ }^{1}$, Prof. R.A. Patel ${ }^{2}$ \\ Student, Electrical, U.V. Patel College of Engineering, Mahesana, India ${ }^{1}$ \\ Associate Professor, Electrical, U.V. Patel College of Engineering, Mahesana, India ${ }^{2}$
}

\begin{abstract}
This paper contains the performance analysis of three phases and five phase induction motor. The mathematical modelling and simulation of Five-phase induction Motor and Three-phase induction Motor is carried out. The simulation results are presented to validate modelling procedure and take a speed and torque waveform of both inductions motor. After that performance analysis of both motors has been discussed. It is concluded that five phase induction motor is more preferred.
\end{abstract}

Keywords: Three-phase inverter fed Induction Motor drive, Five-phase inverter fed Induction Motor drive, MATLAB.

\section{INTRODUCTION}

The first proposal of a variable speed Multi-phase induction motor drive is believed to have been made in after 1969.[1]

Multiphase inverter fed multiphase induction motors has redundant structure, and reliability with high fault tolerant capabilities. Benefits over the traditional three-phase motors are, by reducing the amplitude and increasing the frequency of torque pulsations, lowering the rotor harmonic current losses and dc link current harmonics.[2] Earlier, multiphase motor were not in wide use because of the lack of multiphase supply for the multi-phase motor. With the advancement in power electronics, interest in multi-phase machine has been increased tremendously as high power electronic devices are used as a switch in Voltage Source Inverter (VSI), the output of the VSI is given to the multiphase machine.[1] [6]

A. Three-Phase Supply Voltage, Current \& Power relations[1]

If $V_{\mathrm{RN}}=\mathrm{V}_{\mathrm{YN}}=\mathrm{V}_{\mathrm{BN}}$ and they are equally spaced the systemof voltage is balanced $\left(120^{\circ}\right.$ each phase). $V_{P}=V_{R N}$ $=V_{Y N}=V_{B N}$. Then $V_{L}=\sqrt{ } 3 V_{P}$ and $I_{L}=I_{P}$. Where $I_{L}$ is the current in any line and $\mathrm{I}_{\mathrm{P}}$ is the current in any load or phase.[5]

Total power is,

$\mathrm{P}=3 \mathrm{~V}_{\mathrm{P}} \mathrm{I}_{\mathrm{P}} \cos \emptyset$ or

$\mathrm{P}=\sqrt{3} \mathrm{~V}_{\mathrm{L}} \mathrm{I}_{\mathrm{L}} \cos \varnothing$

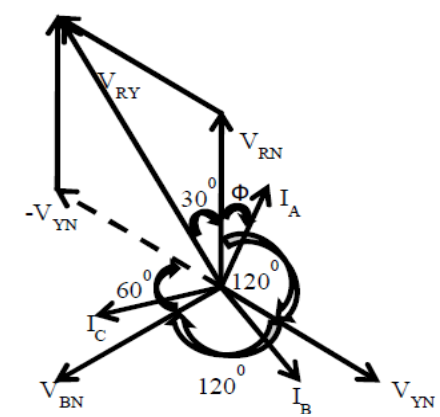

Fig. 1 Phase relationship between phase voltages and currents

B. Five-Phase Supply Voltage, Current \& Power relations [1]

If $V_{\mathrm{AN}}=\mathrm{V}_{\mathrm{BN}}=\mathrm{V}_{\mathrm{CN}}=\mathrm{V}_{\mathrm{DN}}=\mathrm{V}_{\mathrm{EN}}$ and they are equally spaced (i.e.,72 $72^{\circ}$ each phase) $V_{P}=V_{A N}=V_{B N}=V_{C N}=$

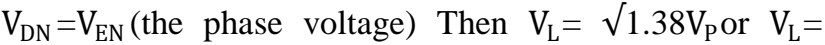
$1.175 \mathrm{~V}_{\mathrm{P}}$ and. $\mathrm{I}_{\mathrm{L}}=\mathrm{I}_{\mathrm{P}}$. The totalpower is the sum of the amount of power in each phase.

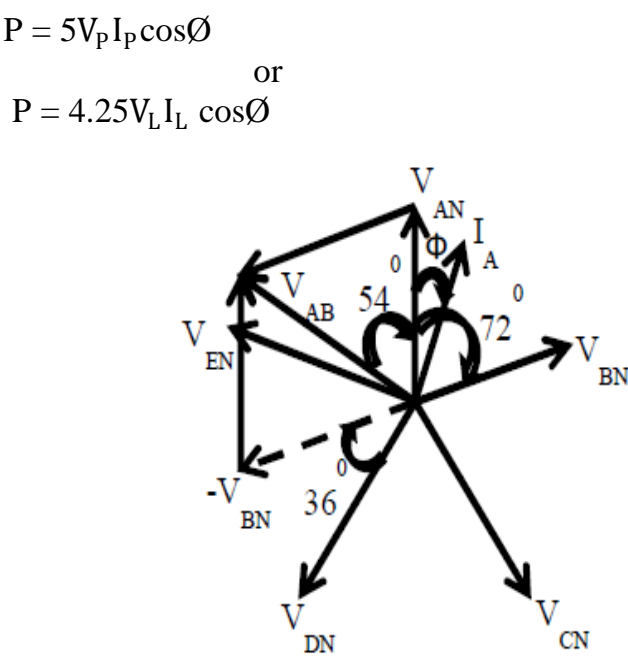

Fig. 2Phase relationship between phase voltages and currents

Supply of Five phase Induction Motor [3]

Voltage source inverter (VSI) used for supply in different phase induction motor.

Single phase VSI used for lower range power application. Three phase VSI used for medium to higher range power application.

Five phase VSI used for above to three phase power application.

The main purpose of these topologies is to provide a fivephase voltage source, where the amplitude, phase, and frequency of the voltages should always be controllable. 


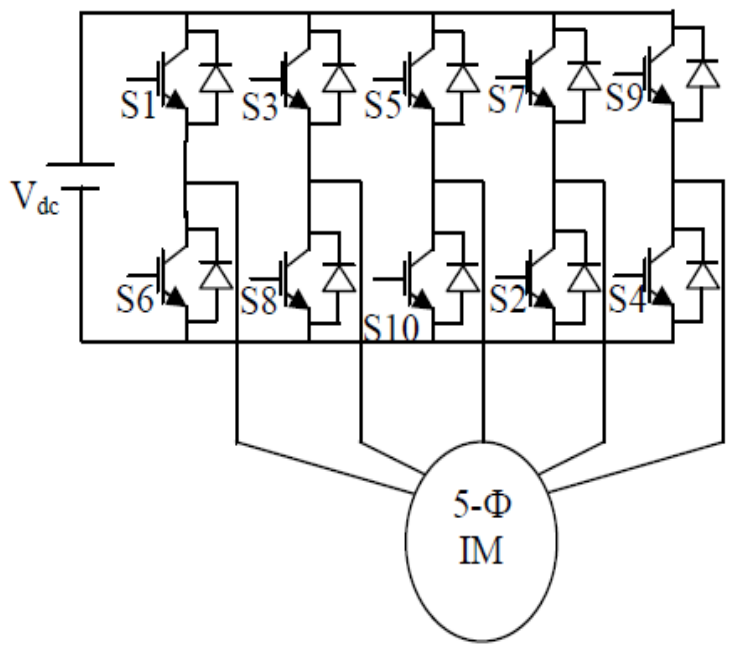

Fig. 3 Five Phase Topology of Five phase of Induction motor

\section{MATHEMATICAL MODELLING OF THREE PHASE INDUCTION MOTOR [4][7]}

Phase voltage of three phase induction motor

$$
\begin{aligned}
& \mathrm{V}_{\mathrm{A}}=\sqrt{2} \mathrm{~V}_{\mathrm{RMS}} \operatorname{SIN}(\Omega \mathrm{T}) \\
& V_{b}=\sqrt{2} V_{r m s} \sin \left(\omega t-\frac{2 \pi}{3}\right) \\
& V_{c}=\sqrt{2} V_{r m s} \sin \left(\omega t-\frac{4 \pi}{3}\right)
\end{aligned}
$$

The flux linkages of stator and rotor $\mathrm{d}-\mathrm{q}$ component can be as follows

$$
\begin{gathered}
\frac{d f_{q s}}{d t}=w_{b}\left[V_{q s}-\frac{w_{e}}{w_{b}} F_{d s}+\frac{R_{s}}{X_{l s}}\left(F_{m q}-F_{q s}\right)\right] \\
\frac{d f_{d s}}{d t}=w_{b}\left[V_{d s}+\frac{w_{e}}{w_{b}} F_{q s}+\frac{R_{s}}{X_{l s}}\left(F_{m q}-F_{d s}\right)\right] \\
\frac{\mathrm{d} f_{q r}}{d t}=-w_{b}\left[\frac{\left(w_{e}-w_{b}\right)}{w_{b}} F_{d r}+\frac{R_{r}}{X_{l r}}\left(F_{q r}-F_{m q}\right)\right] \\
\frac{d f_{d r}}{d t}=-w_{b}\left[-\frac{\left(w_{e}-w_{b}\right)}{w_{b}} F_{q r}+\frac{R_{r}}{X_{l r}}\left(F_{d r}-F_{m d}\right)\right]
\end{gathered}
$$

Where

$$
\begin{gathered}
F_{m d}=X_{m l}\left[\frac{F_{d s}}{X_{l s}}+\right. \\
\left.+\frac{F_{d r}}{X_{l r}}\right] F_{m q}=X_{m l}\left[\frac{F_{q s}}{X_{l s}}+\frac{F_{q r}}{X_{l r}}\right] X_{m l} \\
=\frac{1}{\left(\frac{1}{X_{m}}+\frac{1}{X_{l s}}+\frac{1}{X_{l r}}\right)}
\end{gathered}
$$

Then the equation of the stator and rotor current:-

$$
\begin{aligned}
& i_{q s}=\frac{1}{X_{l s}}\left(F_{q s}-F_{m q}\right) \\
& i_{d s}=\frac{1}{X_{l s}}\left(F_{d s}-F_{m d}\right) \\
& i_{q r}=\frac{1}{X_{l r}}\left(F_{q r}-F_{m q}\right) \\
& i_{d r}=\frac{1}{X_{l r}}\left(F_{d r}-F_{m d}\right)
\end{aligned}
$$

Based on the above equations, the torque and rotor speed can be determined as follows

$$
\begin{gathered}
T_{e}=\frac{3}{2}\left(\frac{P}{2}\right) \frac{1}{\omega_{b}}\left(F_{d s} i_{q s}-F_{q s} i_{d s}\right) \quad \omega_{r} \\
=\int \frac{P}{2 J}\left(T_{e}-T_{L}\right)
\end{gathered}
$$

\section{III.MATHEMATICAL MODELLING OF FIVE PHASE INDUCTION MOTOR[5]}

Modelling of five phase induction motor is nearly same as that of the three phase induction motor hence before going for the modelling of five phase induction motor it was necessary to study the modelling of three phase induction motor. For five phase induction motor five phase supply is required which is then transformed into arbitrary reference frame. The only difference between the five-phase dq induction motor model and three phase dq induction motor model.

Five Phase Stator Voltage of induction machine under balanced condition is expressed as:

$$
\begin{gathered}
V_{a}=\sqrt{2} V_{r m s} \sin (\omega t) \\
V_{b}=\sqrt{2} V_{r m s} \sin \left(\omega t-\frac{2 \pi}{5}\right) \\
V_{c}=\sqrt{2} V_{r m s} \sin \left(\omega t-\frac{4 \pi}{5}\right) \\
V_{d}=\sqrt{2} V_{r m s} \sin \left(\omega t+\frac{4 \pi}{5}\right) \\
V_{e}=\sqrt{2} V_{r m s} \sin \left(\omega t+\frac{2 \pi}{5}\right)
\end{gathered}
$$

Transformation equation to transform machine variable to the variable in the arbitrary reference frame is expressed as: -

$\left[\begin{array}{l}V_{q} \\ V_{d} \\ V_{x} \\ V_{y} \\ V_{0}\end{array}\right]$

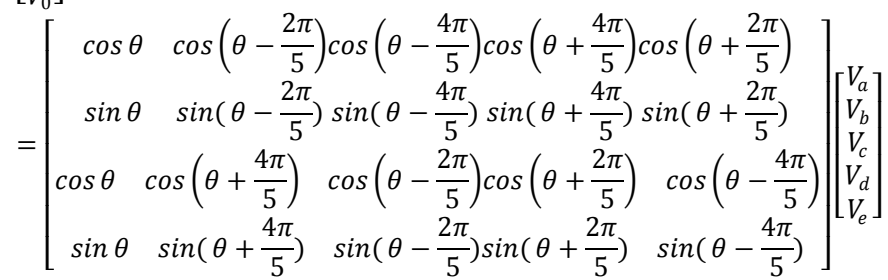

11111

$\overline{2} \overline{2} \overline{2} \overline{2} \overline{2}$

The mathematical equation involved in modelling of five phase induction motor whereas model of five phase induction is shown below

Stator Voltage equation

$$
\begin{gathered}
V_{d s}=R_{s} i_{d s}-\omega_{a} F_{q s}+p F_{d s} \\
V_{q s}=R_{s} i_{q s}+\omega_{a} F_{d s}+p F_{q s} \\
V_{x s}=R_{s} i_{x s}+p F_{x s} \\
V_{y s}=R_{s} i_{y s}+p F_{y s} \\
V_{0 s}=R_{s} i_{0 s}+p F_{0 s}
\end{gathered}
$$

Rotor voltage equation

$$
\begin{gathered}
V_{d r}=R_{r} i_{d r}-\left(\omega_{a}-\omega\right) F_{q r}+p F_{d r} \\
V_{q r}=R_{r} i_{q r}+\left(\omega_{a}-\omega\right) F_{d r}+p F_{q r} \quad V_{d r} \\
=R_{r} i_{d r}-\left(\omega_{a}-\omega\right) F_{q r}+p F_{d r} \\
V_{x r}=R_{r} i_{x r}+p F_{x r} \quad V_{y r}=R_{r} i_{y r}+p F_{y r} \\
V_{0 r}=R_{r} i_{0 r}+p F_{0 r}
\end{gathered}
$$


The flux linkages of stator equation

$$
\begin{gathered}
F_{d s}=\left(X_{l s}+X_{m}\right) i_{d s}+X_{m} i_{d r} \\
F_{q s}=\left(X_{l s}+X_{m}\right) i_{q s}+X_{m} i_{q r} \\
F_{x s}=X_{l s} i_{x s} \\
F_{y s}=X_{l s} i_{y s} \\
F_{0 s}=X_{l s} i_{0 s}
\end{gathered}
$$

The flux linkages of rotor equation

$$
\begin{gathered}
F_{d r}=\left(X_{l r}+X_{m}\right) i_{d r}+X_{m} i_{d s} \\
F_{q r}=\left(X_{l r}+X_{m}\right) i_{q r}+X_{m} i_{q s} \\
F_{x r}=X_{l r} i_{x r} \\
F_{y r}=X_{l r} i_{y r} \\
F_{0 r}=X_{l r} i_{0 r}
\end{gathered}
$$

\section{IV.INDUCTION MOTOR MODEL}

\section{A. Simulink model of three leg inverter}

Device that converts dc input voltage to ac output voltage of desired magnitude and frequency is called an inverter. If the input voltage remains constant the inverter is called a Voltage source inverter and if the input current remains constant it is known as a Current source inverter. Three phase inverters are normally used for medium to high power applications. A Three phase inverter can be obtained from a configuration of six transistors and six diodes as shown. In $180^{\circ}$ conduction mode each transistor conducts for $180^{\circ}$

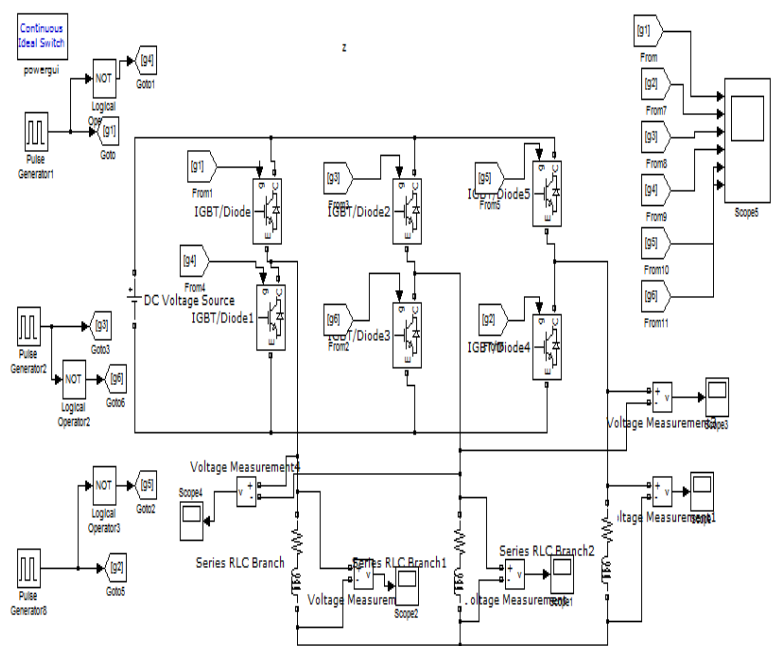

Fig. 9 Simulink Model of Three Leg Inverter

B. Simulink model of five leg inverter

Five phase inverters are normally used for above to high power applications. A Five phase inverter can be obtained from a configuration of ten transistors and ten diodes as shown. In $72^{\circ}$ conduction mode each transistor conducts for $72^{\circ}$.

In single-Leg of VSIs, the two switches (S1 and S6, S3 and $\mathrm{S} 8, \mathrm{~S} 5$ and $\mathrm{S} 10, \mathrm{~S} 7$ and $\mathrm{S} 2$ or S9 and $\mathrm{S} 4$ ) cannot be switched on at a time, because this would result in a short circuit across the dc link voltage supply. Similarly, in order to avoid undefined states in the VSI, and thus undefined ac output line voltages, the switches of any leg of the inverter cannot be switched off simultaneously as this will result in voltages that will depend upon the respective line current polarity.[1]

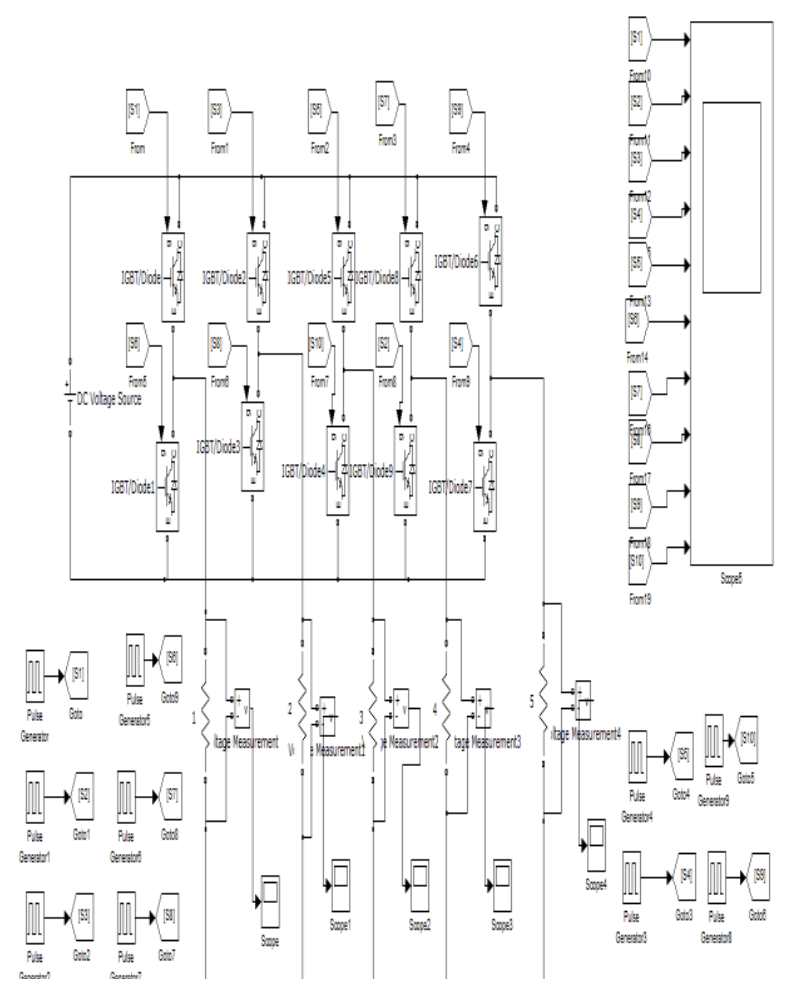

Fig. 10Simulink Model of Five Leg Inverter

C. Simulation of three phase Induction Motor

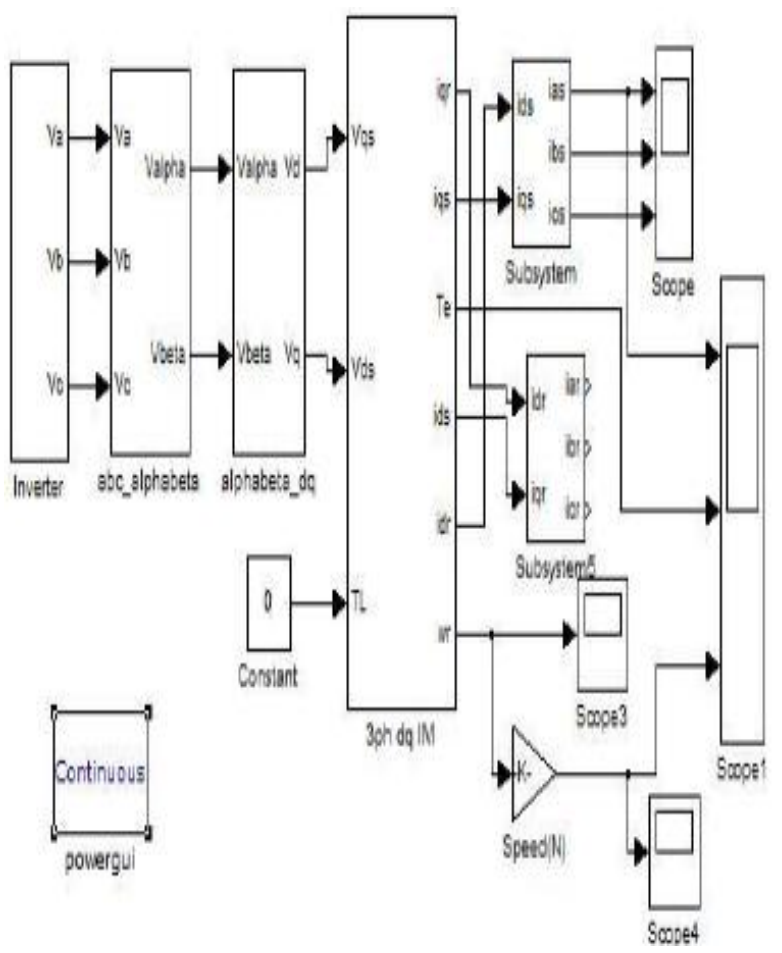

Fig. 10Three Phase Induction Motor Model.

In this model simulation starts with generation of three phase supply which is obtained by using three leg inverter, the output of five leg inverter is used as the supply to the three phase induction motor. 
D. Simulation of Five phase Induction Motor

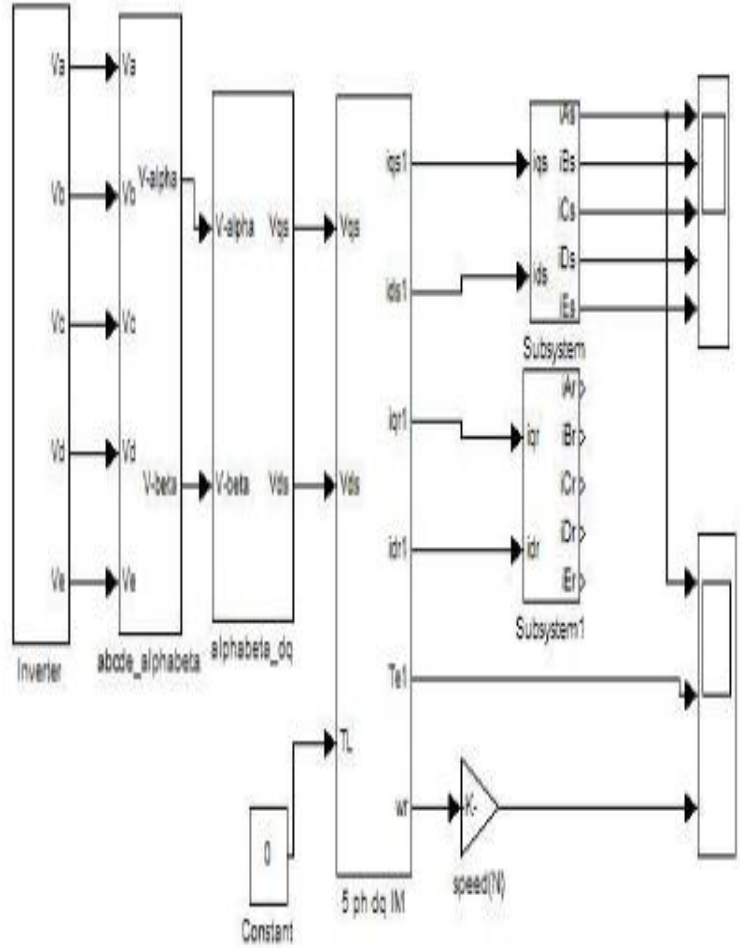

Fig. 11Five Phase Induction Motor Model

In this model simulation starts with generation of five phase supply which is obtained by using five leg inverter, the output of five leg inverter is used as the supply to the five phase induction motor.

\section{MATLAB/SIMULINK RESULT}

A. Output waveform of three phase inverter phase voltage $\propto=\mathbf{1 8 0}^{\circ}$ PHASE VOLTAGE $V_{a}$.

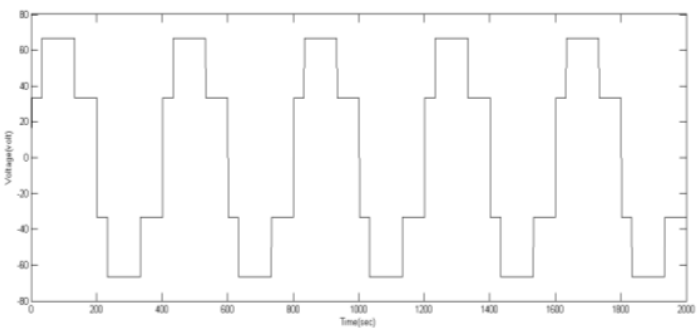

Figure 12:- Phase voltage $V_{a}$

Fig shows the phase voltage $V_{a}$ waveform of 3 phase inverter at $\alpha=180^{\circ}$ of the phase $b$. $X$ axis represent the time in sec and on $\mathrm{Y}$ axis represent the voltage in volt. It starts from $-60 \mathrm{~V}$ and has maximum value of $60 \mathrm{~V}$ and minimum value $-60 \mathrm{~V}$.

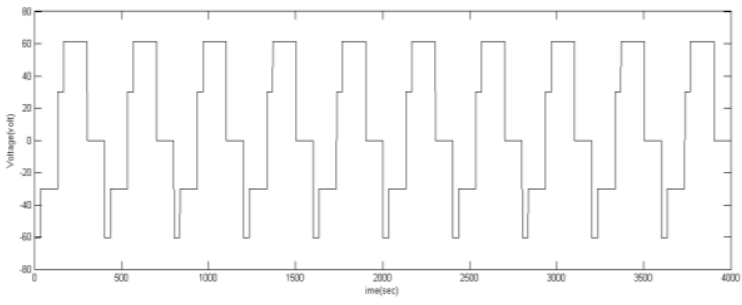

Figure 13:- Phase voltage $V_{b}$
Fig shows the phase voltage $V_{b}$ waveform of 3 phase inverter at $\alpha=180^{\circ}$ of the phase a. $X$ axis represent the time in sec and on $\mathrm{Y}$ axis represent the voltage in volt. It start from zero $\mathrm{V}$ and has maximum value of $60 \mathrm{~V}$ and minimum value $-60 \mathrm{~V}$.

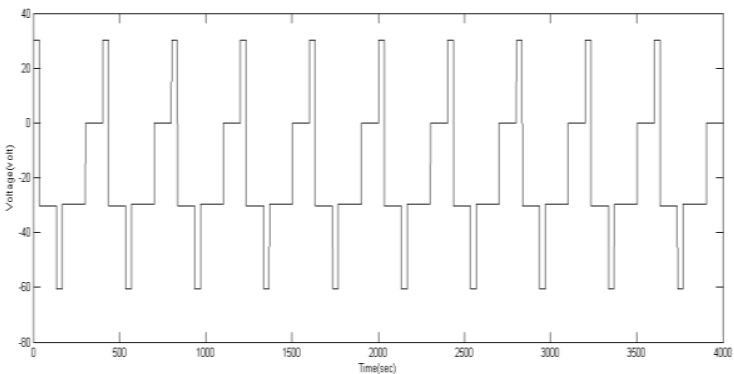

Figure 14:- Phase voltage $V_{c}$

Fig shows the phase voltage $\boldsymbol{V}_{\boldsymbol{c}}$ waveform of 3 phase inverter at $\alpha=180^{\circ}$ of the phase c. $X$ axis represent the time in sec and on $\mathrm{Y}$ axis represent the voltage in volt. It start from $30 \mathrm{~V}$ and has maximum value of $60 \mathrm{~V}$ and minimum value -60

B. Output waveform of five phase inverter phase voltage $\propto=72^{\circ} V_{a}$

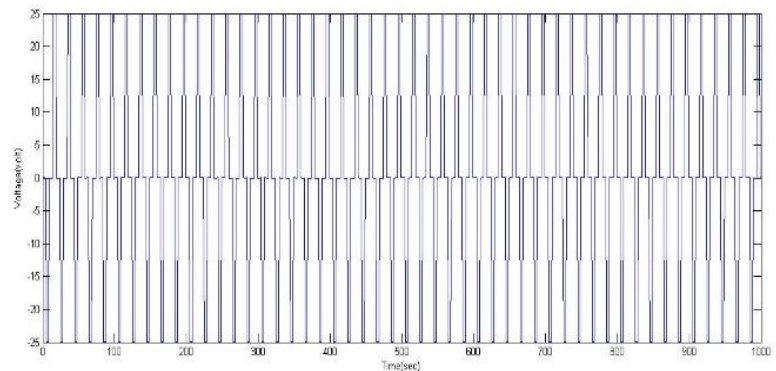

Figure 15:- Phase Voltage $V_{a}$

Fig shows the phase voltage waveform of 5 phase inverter at $\alpha=72^{\circ}$ of the phase a. $X$ axis represent the time in sec and on $\mathrm{Y}$ axis represent the voltage in volt. It start from zero $\mathrm{V}$ and has maximum value of $25 \mathrm{~V}$ and minimum value $-25 \mathrm{~V}$. $\boldsymbol{V}_{\boldsymbol{b}}$

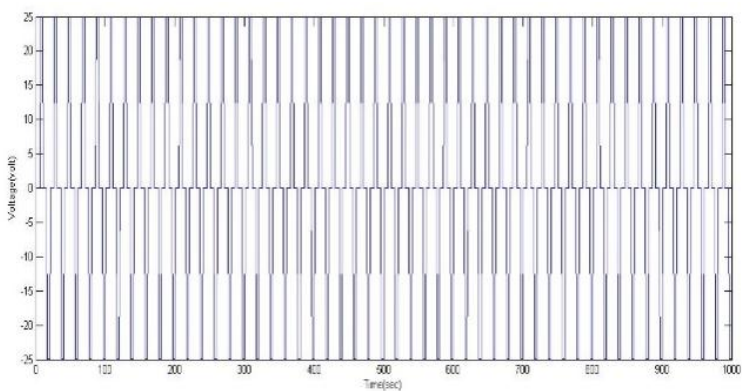

Figure 16:- Phase Voltage $V_{b}$

Fig shows the phase voltage waveform of 5 phase inverter at $\alpha=144^{\circ}$ of the phase a. $\mathrm{X}$ axis represent the time in sec and on $\mathrm{Y}$ axis represent the voltage in volt. It start from zero $\mathrm{V}$ and has maximum value of $25 \mathrm{~V}$ and minimum value $-25 \mathrm{~V} \quad \boldsymbol{V}_{\boldsymbol{c}}$ 
INTERNATIONAL JOURNAL OF INNOVATIVE RESEARCH IN ELECTRICAL, ELECTRONICS, INSTRUMENTATION AND CONTROL ENGINEERING Vol. 4, Issue 1, January 2016

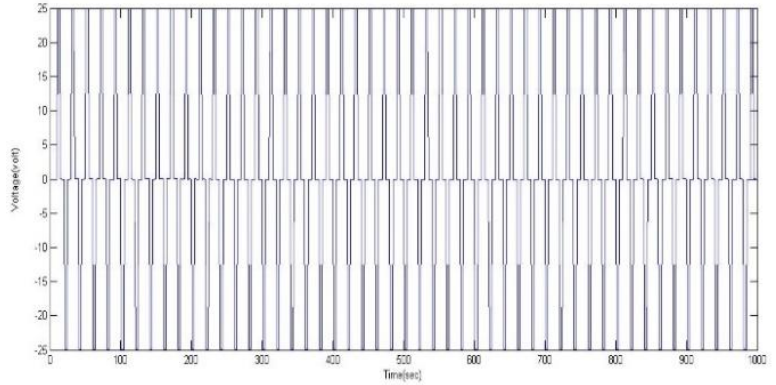

Figure 17:- Phase Voltage $V_{c}$

Fig shows the phase voltage waveform of 5 phase inverter at $\alpha=216^{\circ}$ of the phase a. $\mathrm{X}$ axis represent the time in sec and on $\mathrm{Y}$ axis represent the voltage in volt. It start from zero $\mathrm{V}$ and has maximum value of $25 \mathrm{~V}$ and minimum value $-25 \mathrm{~V} . \boldsymbol{V}_{\boldsymbol{d}}$

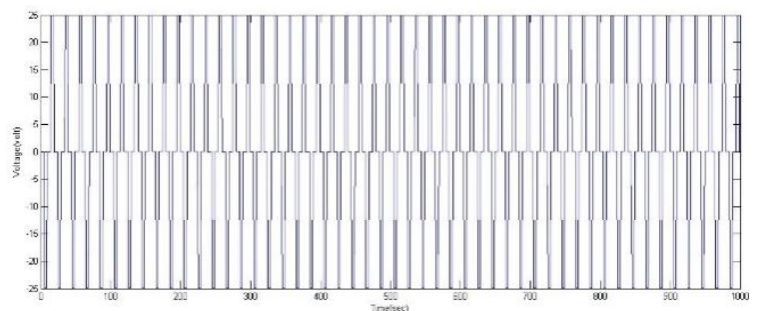

Figure 18:- Phase Voltage $V_{d}$

Fig shows the phase voltage waveform of 5 phase inverter at $\alpha=288^{\circ}$ of the phase a. $\mathrm{X}$ axis represent the time in sec and on $\mathrm{Y}$ axis represent the voltage in volt. It start from zero $\mathrm{V}$ and has maximum value of $25 \mathrm{~V}$ and minimum value $-25 \mathrm{~V}$. $\boldsymbol{V}_{e}$

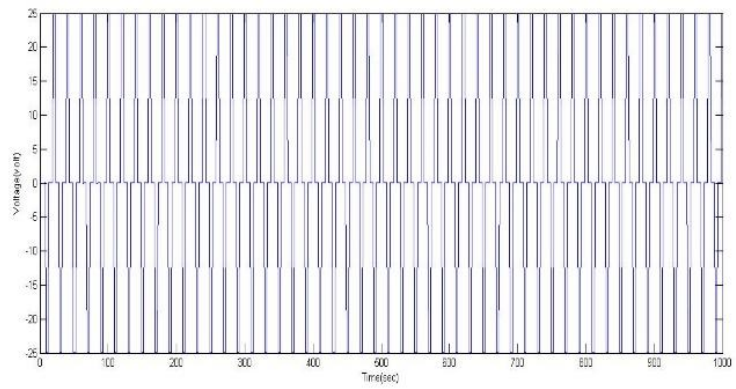

Figure 19:- Phase Voltage $V_{e}$

Fig shows the phase voltage waveform of 5 phase inverter at $\alpha=360^{\circ}$ of the phase a. $\mathrm{X}$ axis represent the time in sec and on $\mathrm{Y}$ axis represent the voltage in volt. It start from zero $\mathrm{V}$ and has maximum value of $25 \mathrm{~V}$ and minimum value $-25 \mathrm{~V}$.

C. Speed waveform of Induction motor

Fig $20 \& 21$ show the speed waveform of three phase induction motor and five phase induction motor.

Fig 24 show the speed vs time waveform when conduction mode $180^{\circ}$ and this clearly indicate that small ripple produce in this speed waveform.

Fig 21 show the speed vs time waveform when conduction mode $72^{\circ}$ and this clearly indicate that ripple content smoothed in this speed waveform.

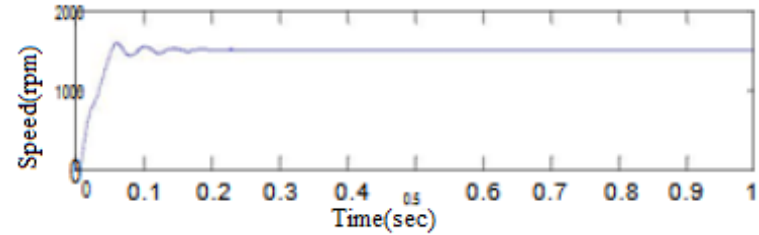

Fig. 20 Speed waveform of three phase induction motor

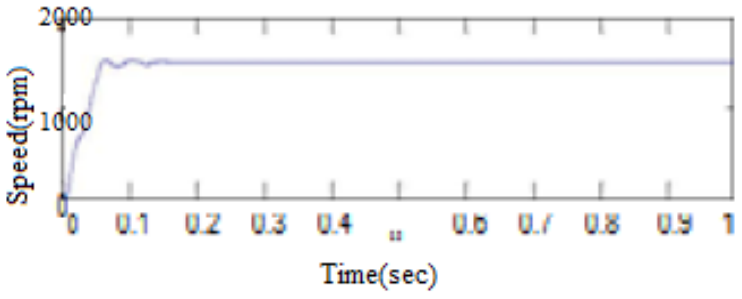

Fig. 21 Speed waveform of five phase induction motor

D. Torque waveform of Induction motor

Fig $22 \& 23$ show the speed and torque waveform of three phase induction motor and five phase induction motor.

Fig 23 show the torque vs time waveform when conduction mode $180^{\circ}$ and this clearly indicate that small ripple produce in this torque waveform

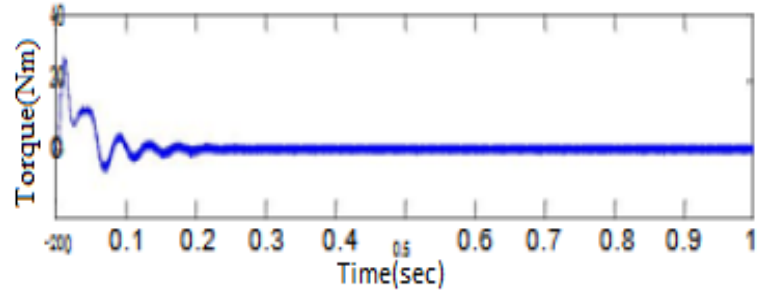

Fig. 22 Torque waveform of three phase induction motor

Fig 23 show the speed vs time waveform when conduction mode $72^{\circ}$ and this clearly indicate that ripple content smoothed in this torque waveform

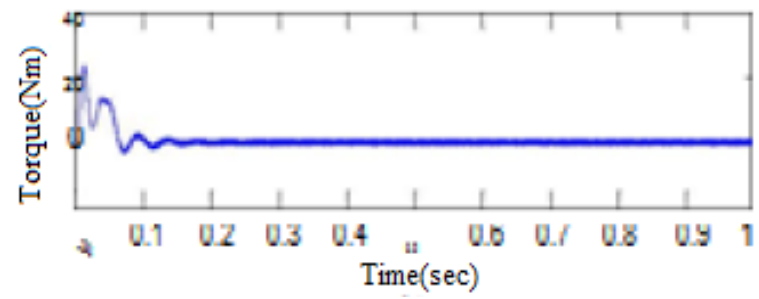

Fig. 23 Torque waveform of five phase induction motor

\section{VI.CONCLUSION}

In this paper compared the three phase and five phase induction motor and a complete simulation model to simulate a three phase and five-phase inverter fed induction motor drive. The simulation model is developed using simpower system block sets of the Matlab/Simulink software. A detailed simulation results are presented to validate the modelling procedure and take a speed and torque waveform of both phase induction motor. In this waveform(speed and toque) ripple produce in three phase induction motor but in waveform(speed and torque) of five phase induction motor ripple can be smoothed so conclude 
that five phase induction motor is preferable for high power application compare to three phase induction motor.

\section{ACKNOWLEDGMENT}

Nothing is impossible without the blessings of god. So, I would like to thank from my heart and soul for giving me ability to prepare the paper. I express my humble gratitude to Prof. R A. Patel who guided me through out and encouraged at every step in this exercise and giving me a chance to work on such a useful and interesting topic and for providing me with his supportive guidance till the completion of the paper. Without their guidance and help this paper would neither have been possible nor in its present shape. I am thankful to all other faculty members as they spent their valuable time in guiding me in my paper. I am very thankful to my parents who supported me the way they can also and at last but not least my sincere thanks to all my friends who supported me and inestimable help providing me the necessary information and help during the preparation of my paper. Because without their support, the completion of my paper was not possible. It is their love that keeps me moving forward.

\section{REFERENCES}

[1] K. P. Prasad Rao, B. Krishna Veni, D. Ravithej "Five-leg inverter for five-phase supply." International Journal of Engineering Trends and Technology- Volume3Issue2- 2012

[2] Prof. Dr. Patrick William Wheeler "Multiphase Induction Motor Drives." Sustainable Energy and Intelligent Systems (SEISCON 2012), IET Chennai 3rd International on Year: 2012

[3] V. Naga Surekha1, A. Krishna Teja, V. Mahesh, N. Sirisha "Sequential Five Leg Inverter for five phase supply." International Journal of Engineering Research and Applications (IJERA) ISSN: 2248-9622 Vol. 2, Issue 3, May-Jun 2012, pp.2798-2802

[4] Naveed Rahaman, H.V. Govindraju. "Modelling \&Simulation of a Three-Phase Electric Traction Induction Motor Using Matlab Simulink."

[5] Palak G.Sharma, S. Rangari "Simulation of Inverter Fed Five Phase Induction Motor "International Journal of Science and Research (IJSR)

[6] K. B. Yadav , Alok Kumar Mohanty , Prabhat Kumar" Recent Research Trend on Multi-phase Induction Machines" Proc. of Int. Conf. on Control, Communication and Power Engineering, CCPE

[7] K. L. SHI, T . F. CHAN, Y. K. WONG and S. L . HO” Modelling and Simulation of the Three-Phase Induction Motor Using Simulink” Int. J. Elect. Enging. Educ., Vol. 36, pp. 163-172. 